\title{
Atmosphere-fire simulation of effects of low-level jets on pyro-convective plume dynamics
}

\author{
Colin C. Simpson $^{\text {a, b }}$, Marwan Katurji ${ }^{\text {b,c }}$, Michael T. Kiefer ${ }^{c}$, Shiyuan Zhong ${ }^{c}$, \\ Joseph J. Charney ${ }^{\mathrm{d}}$, Warren E. Heilman ${ }^{\mathrm{d}}$, and Xindi Bian ${ }^{\mathrm{d}}$ \\ ${ }^{a}$ School of Physical, Environmental and Mathematical Sciences, University of New South Wales at \\ Canberra, Canberra, Australia \\ ${ }^{b}$ Centre for Atmospheric Research, University of Canterbury, Christchurch, New Zealand \\ ${ }^{c}$ Department of Geography, Michigan State University, East Lansing, Michigan, USA \\ ${ }^{\mathrm{d}}$ USDA Forest Service, Northern Research Station, East Lansing, Michigan, USA
}

Email: c.simpson@adfa.edu.au

\begin{abstract}
Blow-up fire behaviour can be broadly defined as a rapid escalation in the intensity or forward rate of spread of a wildland fire, and is often accompanied by extreme pyro-convection associated with rapid smoke release and dispersion. Blow-up fire behaviour is difficult to predict and has been linked to firefighter fatalities, making it an important fire management hazard. Byram (1954) compiled the first observational dataset of categorised wind speed and direction profiles associated with blow-up fire behaviour. Low-level jets, varying in height between 30 and $1000 \mathrm{~m}$ above ground level (AGL), are a common feature in Byram's wind-profile types. Additional studies have qualitatively discussed how low-level jets can influence wildland fire behaviour and pyro-convective plume dynamics. However, there has been little quantitative testing and analysis of the physical processes linking low-level jets and blow-up fire behaviour.

The principle aim of this study was to use the Advanced Regional Prediction System (ARPS) at highresolution, with a $50 \mathrm{~m}$ horizontal grid spacing, to numerically simulate the sensitivity of the downwind pyro-convective plume dynamics to four of the Byram wind-profile types. The Byram wind profiles tested each contain a low-level jet with different properties. A moderate-intensity grass fire was prescribed in the ARPS model domain using a constant surface sensible heat flux of $30 \mathrm{~kW} \mathrm{~m}^{-2}$ in a $150 \times 2500 \mathrm{~m}$ rectangle oriented normal to the prevailing wind.
\end{abstract}

The numerical simulation results indicated that the fire-related atmospheric conditions and large-scale pyro-convective plume structure were sensitive to changes in the low-level jet properties, i.e. wind shear above the jet and the jet height and intensity. However, despite this sensitivity there were some common features in the four numerical simulations. A triangular-shaped fire-perturbed warm air region developed close to the surface downwind of, and extending from, the steady-state parameterized fire. This warm air region was confined spatially by cross-wind inflows that developed due to an interaction of the background winds with the edges of the fire. The horizontal convergence of these cross-wind inflows downwind of the fire marked the starting location of the fire plume. There were considerable updrafts and downdrafts throughout the model domain associated with the pyro-convection.

The heating of air up to several kilometres downwind of the fire would act to preheat fuels, resulting in increased fuel flammability and therefore an enhanced rate of forward fire spread. Additionally, the atmospheric turbulence directly over this warm air region and the updrafts and downdrafts associated with the fire plume would affect the transportation of firebrands downwind of the fire. The downwind transportation of firebrands can ignite spot fires, which enhance the forward rate of fire spread as the spot fires grow and merge with the existing fire front. Through these mechanisms the low-level jet wind profiles can be directly linked with blow-up fire behaviour.

The numerical simulations performed with ARPS were highly idealised and therefore subject to a number of limitations. For example, temporal variations in the prescribed fire intensity and shape, directional wind shear, background turbulence and moist processes were not modelled in this study. However, future work will gradually address these limitations through further numerical simulations using both ARPS and a coupled atmosphere-fire model.

Keywords: Blow-up fire behaviour, atmosphere-fire numerical modelling, pyro-convective plume dynamics 


\section{INTRODUCTION}

Byram (1954) compiled the first observational dataset of wind speed and direction profiles associated with 17 blow-up fires that occurred between 1936 and 1953 in the US. Byram categorised these wind profiles into a number of different types and related each type to observed blow-up fire behaviour. In this study, blow-up fire behaviour refers to a rapid increase in fire intensity or forward rate of fire spread that is often accompanied by extreme pyro-convection, although there has been no subsequent standardization of the definition of blow-up fire behaviour in the fire research and management literature (Potter, 2012).

Low-level jets, varying in height from 30 to $1000 \mathrm{~m}$ above ground level (AGL), are a common feature in Byram's wind profiles, particularly types 1-3. Specific aspects of blow-up fire behaviour, such as spotting and fire whirl formation, are believed to be associated with low-level jet properties, i.e. jet height and intensity, and wind shear above the jet. The terms "wind-dominated" and "plumedominated" are commonly used in the fire research and management literature to qualitatively describe whether advective or convective forces are predominantly driving fire behaviour. Byram (1954, 1959) proposed that a relative balance between advective and convective forces could be an important factor in blow-up fire behaviour.

Numerous studies have expanded on Byram's work by evaluating the wind conditions, and in some cases the advective and convective forces, associated with wildland fires that broadly fit Byram's original definition of blow-up fire behaviour (Schaefer, 1957; Small, 1957; Kiil and Griegel, 1969; Wade and Ward, 1973; Nimchuk, 1983; Simard et al., 1983). Kiil and Griegel (1969) investigated blow-up fires associated with low-level jets and found that these fires were accompanied by considerable fire whirl formation. Wade and Ward (1973) investigated the wind profiles and the convective and advective forces for the 1971 Air Force Bomb Range fire in North Carolina. They proposed that cyclic pyro-convective plume development and spotting, driven by downwind ember propagation, were important factors in the observed fire behaviour.

A number of additional studies have discussed qualitatively why Byram's wind profiles could be associated with blow-up fire behaviour (Arnold and Buck, 1954; Steiner, 1976; Clark et al., 1996a,b). Arnold and Buck (1954) proposed that if a fire plume penetrates a stable inversion, it can allow a sudden change in fire behaviour as drier, higher momentum air from above the inversion mixes down to the ground. Steiner (1976) argued that an interaction of the upwind convergence and the fire plume could increase the convergence at the fire when the wind speed decreases with height (referred to as negative wind shear in this study).

Blow-up fires are a considerable fire management hazard, due to their unpredictable and high intensity fire behaviour, and have been linked to past firefighter fatalities (Viegas, 2009). Potter (2012) stated that there would be value in further study of blow-up fires, based on the concept of wind profile critical levels discussed by Kiefer et al. (2008, 2009). Numerical modelling offers a flexible research platform that can be optimized for investigating atmosphere-fire feedbacks, especially in the context of criticallevel analysis. In recent years there has been extensive effort devoted towards developing atmospherefire modelling systems (Clark et al., 1996a,b; Coen et al., 2013; Linn et al., 2002).

The principle aim of this study is to use high-resolution numerical modelling to investigate the sensitivity of fire-atmospheric conditions and pyro-convective plume dynamics to a subset of Byram's wind profiles that include low-level jets. At present there is little understanding of how these wind profiles affect potential temperatures, vertical velocities, turbulent kinetic energy (TKE) and downstream fire plume structure and smoke dispersion. Investigating the feedback of low level jets and the accompanied wind shear on atmospheric properties could aid in better understanding the conditions that yield to blow-up fire behaviour, and near-fire and downstream smoke dispersion associated with the resulting plume dynamics.

\section{METHODOLOGY}

The Advanced Regional Prediction System (ARPS) was used to numerically simulate the feedback of four of Byram's wind profiles, shown in Figure 1, on the pyro-convective plume dynamics. ARPS was developed by the Center for Analysis and Prediction of Storms at the University of Oklahoma (Xue et al., 2000) and is a non-hydrostatic compressible flow solver of the Navier-Stokes equations applied to a land-atmosphere interaction system. ARPS is used in operational weather forecasting and has been validated for real weather simulations in complex terrain (Chow et al., 2006; Wiegel et al., 2006). Kiefer et al. $(2008,2009)$ used ARPS to study modes of pyro-convection under varying wind conditions at micro-scale spatial resolutions of less than $100 \mathrm{~m}$. 
The model domain had flat terrain and extended $30 \times 7.5 \mathrm{~km}$ horizontally in the west to east $(\mathrm{x})$ and south to north (y) directions, with a chosen horizontal grid spacing of $50 \mathrm{~m}$. The vertical grid spacing was chosen as $20 \mathrm{~m}$ from the lowest model level, at $10 \mathrm{~m} \mathrm{AGL}$, to $3 \mathrm{~km}$ AGL. Between $3 \mathrm{~km}$ AGL and the model domain top at 8.8 $\mathrm{km}$ AGL, the vertical grid spacing was stretched following a hyperbolic tangent function, with a maximum vertical grid spacing of $100 \mathrm{~m}$. Only the model results up to a height of $3 \mathrm{~km}$ AGL are discussed here, as these are of greatest relevance in this study. The time-averaged fields used in the analysis were averaged over a $2 \mathrm{hr}$ period using $1 \mathrm{~min}$ instantaneous model output, from a lapsed time of 30 to $150 \mathrm{~min}$ from simulation start time.

A fire was represented in ARPS by a prescribed constant surface sensible heat flux of $30 \mathrm{~kW} \mathrm{~m}^{-2}$, which approximates a medium intensity fire. The heat source had a width of $150 \mathrm{~m}$ along the $\mathrm{x}$-direction and was located $5 \mathrm{~km}$ in from the western lateral boundary. The heat source stretched $2.5 \mathrm{~km}$ along the y-direction and was centered on the y-axis. The background atmospheric stability was neutral throughout the depth of the modelled atmosphere and all surface heat exchange between the surface and the atmosphere was turned off except where the heat source was introduced, with no moist processes included. The west-east boundary conditions were set with a zero normal gradient (Neumann type), whereas the north-south boundary conditions were set with periodic conditions.

\section{RESULTS AND DISCUSSION}

In all four cases, the parameterised fire heated the immediately adjacent near-surface (10 $\mathrm{m} \mathrm{AGL)} \mathrm{air} \mathrm{to}$ about $12-20 \mathrm{~K}$ above the ambient potential temperature of $300 \mathrm{~K}$. The fire-heated air was then advected downwind from the fire, as shown in Figure 2, forming a triangular-shaped warm air region close to the surface. Within this triangular-shaped region, the potential temperature decreased with distance away from the fire. This increase in the downwind near-surface air temperature would act to increase local fuel temperatures and therefore also the fuel flammability, particularly of fine fuels. Increased fuel flammability through fuel pre-heating prior to the arrival of the fire front would act to increase the forward rate of fire spread as it would take less time to bring the fuel up to its ignition temperature.

Near-surface cross-wind inflows, along the y-direction, were formed in all four cases at the southern and northern edges of the fire, as shown in Figure 2. These cross-wind inflows acted to spatially confine the fire-perturbed warm air as it was advected downwind, resulting in the distinctive triangular geometry of the heated region. The point of convergence of the southerly and northerly cross-wind inflows marked the end of the near-surface warm air region. The cross-wind inflow wind speeds were broadly similar in all four cases and peaked at approximately $6-8 \mathrm{~m} \mathrm{~s}^{-1}$. The downwind extension of the triangular-shaped fire-heated region was highly sensitive to the wind speed profile and was about 3,5 , 7 and $10 \mathrm{~km}$ for the type 2-a, 2-b, 3-b and 3-c Byram wind profiles, respectively.

The time-averaged fire plume structure and vertical velocities are shown in Figure 3 . The fire intensity was not sufficient to initiate significant pyro-convection directly over or adjacent to the fire. Instead, the fire plume updraft only became evident starting at the point of convergence of the cross-wind inflows downwind of the fire. This physically represents the location at which the converging air became positively buoyant and began ascending. The distance at which the fire plume began downwind of the fire was therefore also highly sensitive to changes in the wind speed profile. 

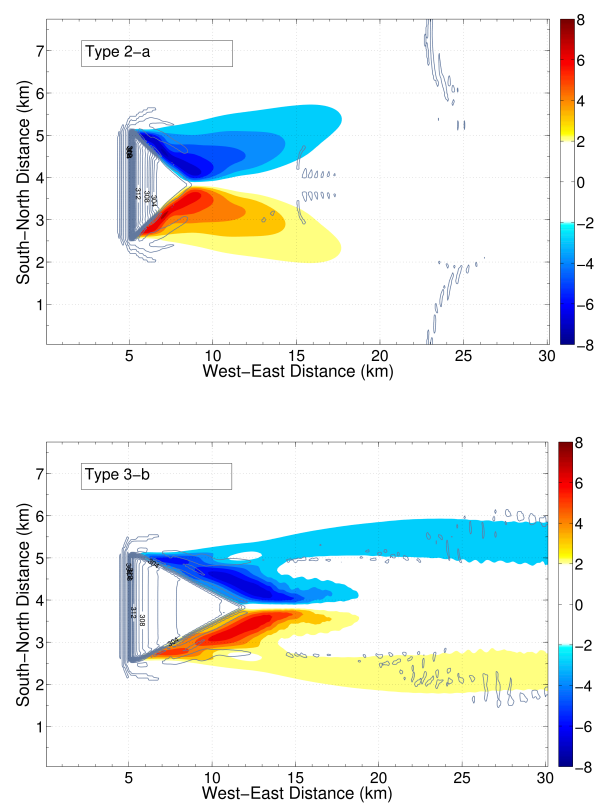
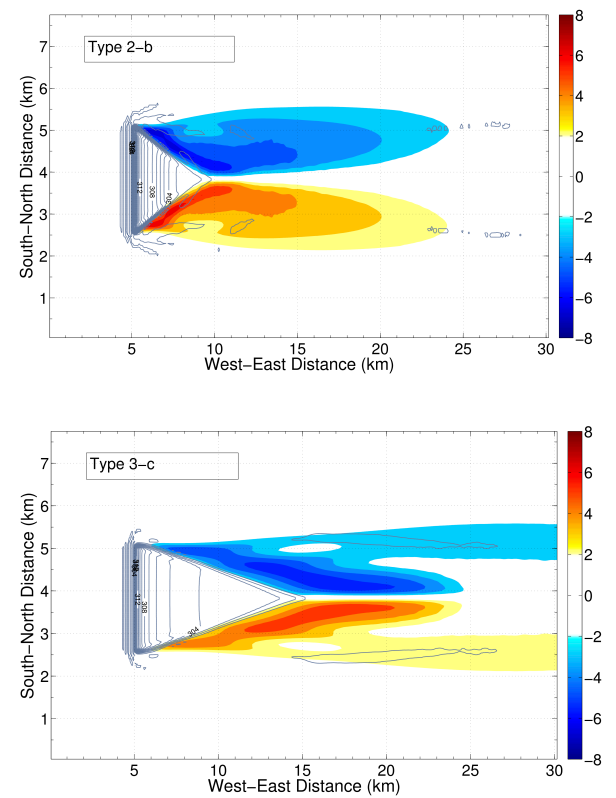

Figure 2. Time-averaged (from $1 \mathrm{~min}$ model output over $2 \mathrm{hr}$ ) $v$-velocity component (south-north) colour-shaded contours overlaid with contour lines ( $2 \mathrm{~K}$ interval) of potential temperature for an $x-y$ cross section at $10 \mathrm{~m}$ AGL.

In each case there was a single main updraft core similar in width to the fire, as shown in Figure 3. The fire plume structure reached an approximate steady-state after about $30 \mathrm{~min}$ for the type 2-b, 3-b and 3$\mathrm{c}$ wind profiles. In contrast, the fire plume structure for the type 2-a wind profile underwent a considerable change between 90 and $100 \mathrm{~min}$. The inclination of the main updraft core increased relative to the ground in this 10 min period, resulting in the two apparent updraft cores seen in Figure 3a. The time-averaged fire plume structure was then approximately constant for the remainder of the simulation.

After $100 \mathrm{~min}$, the leading edge of the fire plume for the type 2-a wind profile was inclined approximately $28^{\circ}$ from the ground, with instantaneous vertical wind speeds exceeding $10 \mathrm{~m} \mathrm{~s}^{-1}$ (not shown). The fire plume for the type 2-b case had a similar mean updraft velocity to type 2 -a, although the leading edge of the fire plume was inclined at a lower angle relative to the ground, about $20^{\circ}$, due to the higher wind speeds in the type 2-b wind profile. In comparison, the leading edge of the fire plume was inclined at around $14^{\circ}$ and $9^{\circ}$ for the type 3-b and 3-c wind profiles, respectively.

The fire plume had a relatively stronger updraft core for the type 3-b and 3-c wind profiles. The main updraft core was located at a higher height relative to the position of the main updraft core for the type 2 -a and 2-b cases. The updraft core height and fire plume inclination angle appear to be associated with the wind shear above the jet and the height of the point of inflection in the wind shear, which is approximately $1000 \mathrm{~m}$ AGL for the type 3-b and 3-c wind profiles. These results suggest that, contrary to Byram (1954), updraft cores can exist for the type 3-b and 3-c wind profiles, despite the strong positive wind shear above the jet which Byram (1954) suggested would break down any pyroconvective column.

These results support the concept that fire plumes occurring under these wind speed profiles can potentially transport firebrands long distances downwind. Firebrands produced by the fire could be blown downwind close to the ground by the turbulent near-surface winds, before being lofted in the updraft of the fire plume. The transportation of firebrands downwind by the near-surface winds and fire plume has the potential to ignite spot fires ahead of the main fire front. The effect of extensive downwind spotting is to enhance the fire spread rate as the spot fires grow and merge with the preexisting fire front. This mechanism therefore provides a direct link between the fire plume structure and blow-up fire behaviour.

Figure 3 indicates that a wave-like interface, with alternating updrafts and downdrafts, was present between the ambient air and the leading edge of the fire plume in all four cases. Vertical return circulations can be seen on the outside of the fire plume, indicated by blue shading in the right-hand figures, which constrains the horizontal extent of the fire plume along the y-direction. In Figure $3 \mathrm{~d}$ 
a

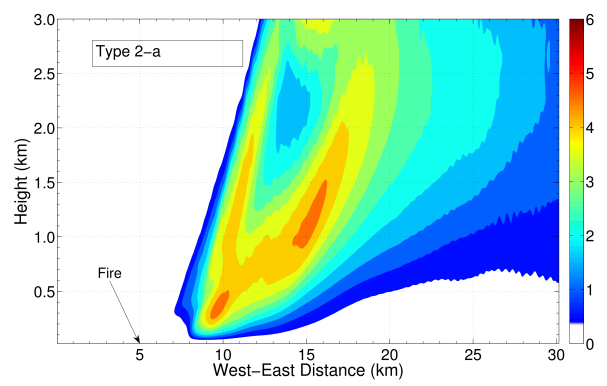

c
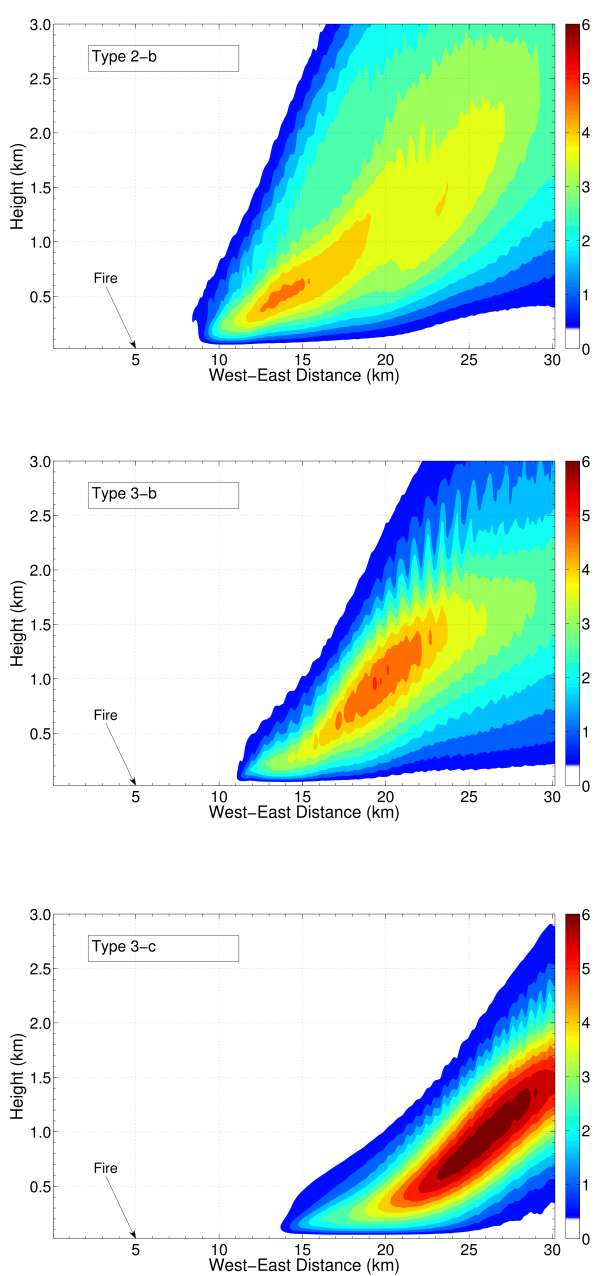

b

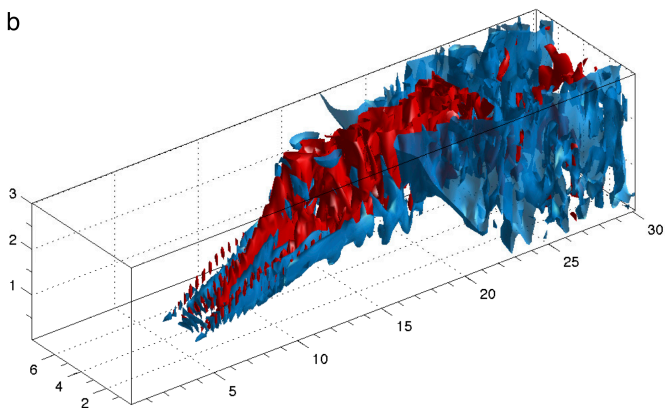

d

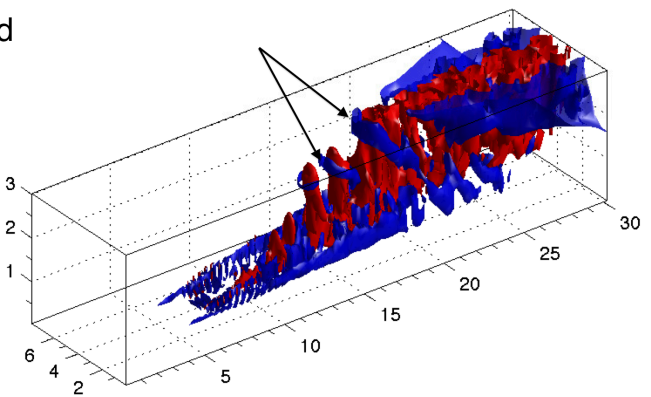

f

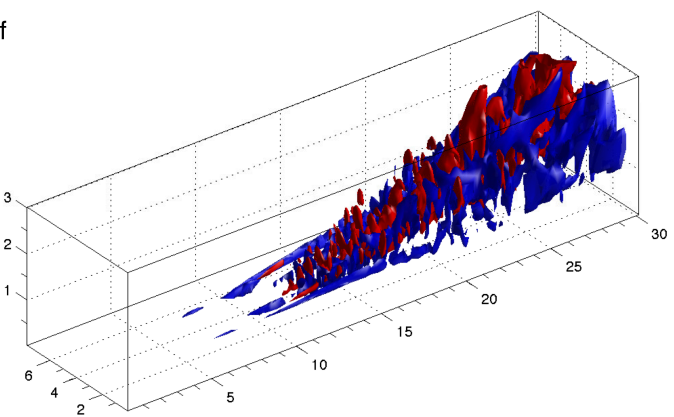

h

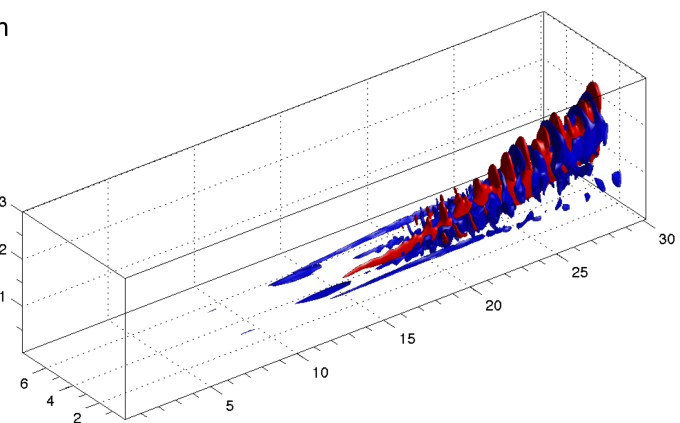

Figure 3. Left column: time-averaged (from $1 \mathrm{~min}$ model output over $2 \mathrm{hr}$ ) $w$-velocity from a $x-z$ cross section along the fire's central line running west to east of the domain. Right column: a snapshot iso-surface (at $2 \mathrm{hr}$ ) of the $w$-velocity at $3 \mathrm{~m} \mathrm{~s}^{-1}$ (red) and $-1.5 \mathrm{~m} \mathrm{~s}^{-1}$ (blue).

there is evidence of a downdraft wrapping around the leading and outside edges of an updraft cell at the leading edge of the plume (indicated by black arrows). These downdrafts would provide a mechanism for quickly returning lofted firebrands to the ground. The small spatial scale of these updraft and downdraft cells suggests that it would be valuable to consider higher spatial resolution numerical modelling of the fire plume behaviour in future research.

Although not shown here, the model parameterised TKE at $10 \mathrm{~m}$ AGL is typically greater than $1 \mathrm{~m}^{-2} \mathrm{~s}^{-2}$ over the fire-perturbed warm air region and close to zero outside of this region. These results are broadly consistent with observations of spotting and fire whirls for blow-up fires associated with these four wind profiles. However, the model spatial resolution is too coarse to directly resolve the turbulent atmospheric motions in the immediate vicinity of the fire. 


\section{SUMMARY AND CONCLUSIONS}

This study provides an initial attempt at numerically modelling the effects of Byram's low-level jet wind profiles, which are associated with blow-up fire behavior, on the downwind air temperature and pyro-convective plume dynamics. The modelled pyro-convective plume began downwind from the fire due to positive buoyancy at the point of convergence of the cross-wind inflows. These inflows originated from an interaction between the background winds and the fire edges. The resulting fire plume dynamics and near-fire warm air region were highly sensitive to changes in the low-level jet properties, i.e. wind shear above the jet and the jet height and intensity.

Low-level jets are not restricted to flat topography and are fairly common in complex topography such as valleys, ridge tops and above forest canopies. The results outline the detailed evolution of the pyroconvective plume from the modelled fire source to $25 \mathrm{~km}$ downstream; with direct implications for fire smoke spread and mixing along this spatial scale under the investigated atmospheric conditions. The low-level jet properties are directly linked to blow-up fire behaviour through their ability to affect the downwind transportation of firebrands, by the near-fire turbulence and fire plume, and the preheating of fuels ahead of the fire.

There are a number of limitations to this study, which will be addressed in future work. The neutral background stability might not be a true representation of the real stability during blow-up fire behaviour, which is usually associated with unstable conditions. Temporal changes in fire intensity and shape, directional wind shear, background turbulence and moist processes were not modelled in this study, however they could each have considerable implications for the fire-atmospheric dynamics.

Future work will include additional simulations to address these limitations, and will also include simulation at higher spatial resolution to resolve the near-fire (tens of meters from the fire source) atmospheric dynamics and its relation to blow-up fire conditions. This future research will also allow for the identification of common patterns and features of the fire-atmospheric conditions and pyroconvective plume dynamics in response to varying low-level jet properties. It would also be valuable to use a coupled atmosphere-fire model to examine more directly the impact of the two-way coupled atmosphere-fire feedbacks on the fire intensity, forward rate of fire spread and smoke dispersion under different low-level jet conditions.

\section{ACKNOWLEDGEMENTS}

This research was partially supported by the US Forest Service Joint Fire Science Program (Project \#09-1-04-1). The simulations were performed on the BlueFern supercomputer, managed and operated by the High Performance Computing Centre at the University of Canterbury, New Zealand

\section{REFERENCES}

Arnold, R.K. and Buck, C.C. (1954). Blow-up fires - silviculture or weather problems? Journal of Forestry, 52(6), 408-411.

Byram, G.M. (1954). Atmospheric conditions related to blowup fires. Station Paper 35. US Department of Agriculture, Southeastern Forest Experiment Station, Ashville, NC.

Byram, G.M. (1959). Combustion of forest fuels. Forest Fire: Control and Use, 1, 61-89.

Chow, F.K., Andreas, P.W., Robert, L.S., Mathias, W.R. and Ming, X. (2006). High-resolution largeeddy simulations of flow in a steep alpine valley. Part I: Methodology, verification, and sensitivity experiments. Journal of Applied Meteorology and Climatology, 45, 63-86.

Clark, T.L., Jenkins, M.A., Coen, J.L. and Packham, D.R. (1996a). A coupled atmosphere-fire model: Convective feedback on fire-line dynamics. Journal of Applied Meteorology, 35, 875-901.

Clark, T.L., Jenkins, M.A., Coen, J.L. and Packham, D.R. (1996b). A coupled atmosphere-fire model: Role of the convective Froude number and dynamic fingering at the fireline. International Journal of Wildland Fire, 6(4), 177-190.

Coen, J.L., Cameron, M., Michalakes, J., Patton, E.G., Riggan, P.J. and Yedinak, K.M. (2013). WRFFire: Coupled weather-wildland fire modeling with the Weather Research and Forecasting model. Journal of Applied Meteorology and Climatology, 52, 16-38. 
Kiil, A.D. and Griegel, J.E. (1969). The May 1968 forest conflagration in central Alberta: A review of fire weather, fuels and fire behaviour. Canadian Forestry Service, Information Reports Digest, A-X$24,26 \mathrm{pp}$.

Kiefer, M.T., Lin, Y.L. and Charney, J.J. (2008). A study of two-dimensional dry convective plume modes with variable critical level height. Journal of the Atmospheric Sciences, 65, 448-469.

Kiefer, M.T., Parker, M.D. and Charney, J.J. (2009). Regimes of dry convection above wildfires: idealized numerical simulations and dimensional analysis. Journal of the Atmospheric Sciences, 66, 806-836.

Linn, R., Reisner, J., Colman, J.J. and Winterkamp, J. (2002). Studying wildfire behaviour using FIRETEC. International Journal of Wildland Fire, 11, 233-246.

Nimchuk, N. (1983). Wildfire behaviour associated with upper ridge breakdown. Alberta Energy and Natural Resources Forest Service, Edmonton, Alberta. Report Number T/50.

Potter, B.E. (2012). Atmospheric interactions with wildland fire behaviour - I. Basic surface interactions, vertical profiles and synoptic structures. International Journal of Wildland Fire, 21, 779-801.

Schaefer, V.J. (1957). The relationship of jet streams to forest wildfires. Journal of Forestry, 55(6), 419-425.

Simard, A.J., Haines, D.A., Blank, R.W. and Frost, J.S. (1983). The Mack Lake Fire. USDA Forest Service, North Central Forest Experiment Station, St Paul, MN. General Technical Report NC-83.

Small, R.T. (1957). The relationship of weather factors to the rate of spread of the Robie Creek Fire. Monthly Weather Review, 85(1), 1-8.

Steiner, J.T. (1976). Blow-up fires - the Byram wind profile. Australian Meteorological Magazine, 24(3), 139-142.

Viegas, D.X. (2009). Recent Forest Fire Related Accidents in Europe. European Commission, Joint Research Centre, Institute for Environment and Sustainability.

Wade, D.D. and Ward, D.E. (1973). An analysis of the Air Force Bomb Range Fire. USDA Forest Service, Southeast Forest Experiment Station, Ashville, NC. Research Paper SE-105.

Wiegel, A., Chow, F.K., Mathias, W.R., Robert, L.S. and Ming, X. (2006). High-resolution large-eddy simulations of flow in a steep alpine valley. Part II: Flow structure and heat budgets. Journal of Applied Meteorology and Climatology, 45, 87-107.

Xue, M., Droegemeier, K.K. and Wong, V. (2000). The Advanced Regional Prediction System (ARPS) - A multi-scale nonhydrostatic atmospheric simulation and prediction model. Part I: Model dynamics and verification. Meteorology and Atmospheric Physics, 75, 463-485. 